\title{
DFT studies of gas hydrate formation
}

Daniel G. S. Quattrociocchi*(PG), Camila R. de A. Neves (IC), Leonardo M. Costa (PQ), José Walkimar de M. Carneiro(PQ).

Programa de Pós-graduação em Química, Departamento de Química Inorgânica e Departamento de Química Orgânica, Universidade Federal Fluminense, Outeiro de São João Batista s/n 24020-14.

*Corresponding author: E-mail:_daniel_garcez@yahoo.com.br

Key words: DFT, hydrate, interaction energy, gas encapsulation, hydrogen bond

\section{Introduction}

Hydrates are non-stoichiometric crystalline solids composed of water molecules interacting with each other through hydrogen bonds to produce cage structures encapsulating low molecular weight gases. ${ }^{1,2}$ The methane hydrates has attracted great interest as energy source and $\mathrm{CO}_{2}$ hydrates area a potential way for $\mathrm{CO}_{2}$ storage. However, the structural features responsible for their formation and stability are not clear enough and need further work.

\section{Metodology}

DFT calculations were performed using the B97D functional and the $6-31+\mathrm{G}(\mathrm{d})$ basis set. Implicit solvent was represented the polarizable continuum model (PCM). The interaction energy, entalpy and Gibbs free energy were calculated by the equation: $\Delta X=$ $\mathrm{X}_{\text {hydrate }}-\left(\mathrm{X}_{\text {guest }}+\mathrm{X}_{\text {host }}\right)$.

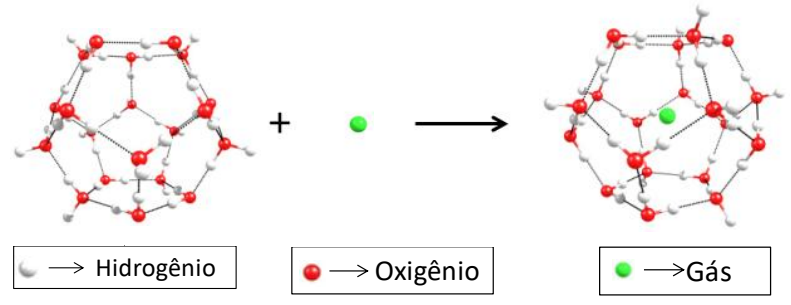

Figure 1: Scheme for the formation of gas hydrates with a $5^{12}$ cavity ( 20 water molecules).

\section{Results and discussion}

The full optimized structures are shown in figure 2.

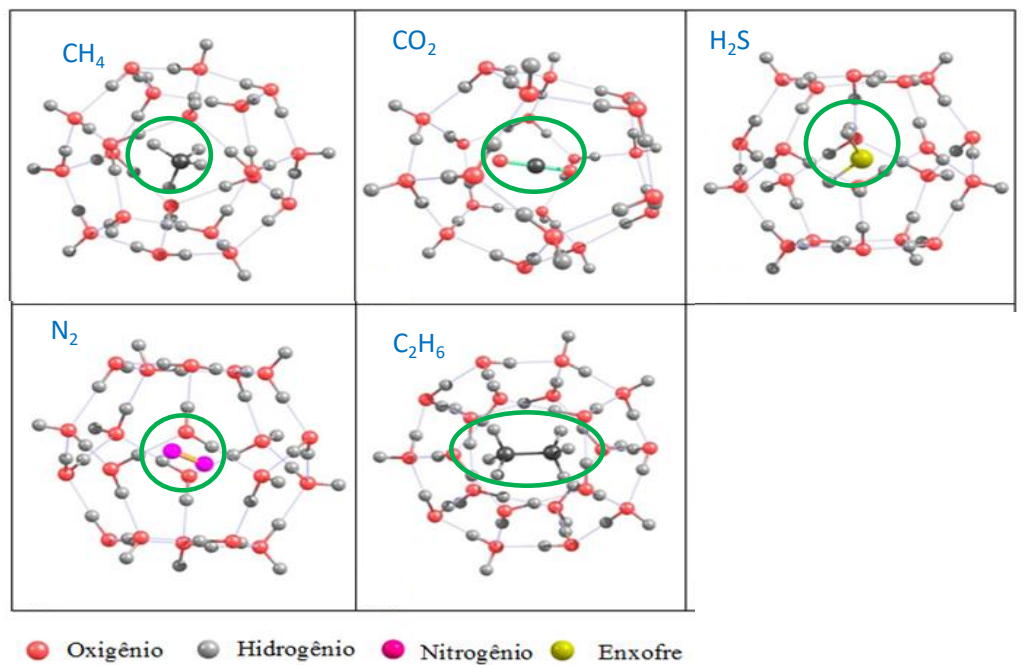

Figure 2: Optimized structures of $\mathrm{CH}_{4}, \mathrm{CO}_{2}, \mathrm{H}_{2} \mathrm{~S}, \mathrm{~N}_{2}$ and $\mathrm{C}_{2} \mathrm{H}_{6}$ encapsulated in $5^{12}$ hydrate cavity. 
The methodology was applied for the five systems with the gases: $\mathrm{CH}_{4}, \mathrm{CO}_{2}, \mathrm{H}_{2} \mathrm{~S}, \mathrm{~N}_{2}$ and $\mathrm{C}_{2} \mathrm{H}_{6}$. The results obtained are listed in table 1 .

Table 1: Interaction Energy $(\Delta \mathrm{E})$, Enthalpy $(\Delta \mathrm{H})$, Gibbs Free Energy $\left(\Delta \mathrm{G}^{298}\right)$, Entropy $(\Delta \mathrm{S})$ and cage volume

\begin{tabular}{|c|c|c|c|c|c|}
\hline gas & $\begin{array}{c}\Delta \mathrm{E} \\
\left(\text { Kcal.mol }^{-1}\right)\end{array}$ & $\begin{array}{c}\Delta \mathbf{H} \\
\left(\text { Kcal.mol }^{-1}\right)\end{array}$ & $\begin{array}{c}\Delta \mathrm{G}^{298} \\
\left(\mathrm{Kcal} . m o l^{-1}\right)\end{array}$ & $\begin{array}{c}\Delta S \\
\left(\text { cal.mol }^{-1}\right) \\
\end{array}$ & $\begin{array}{c}\mathbf{V} \\
\left(\AA^{3}\right)\end{array}$ \\
\hline $\mathrm{N}_{2}$ & -2.03 & -2.63 & 4.18 & -22.8 & 48.84 \\
\hline $\mathrm{CH}_{4}$ & -3.74 & -4.33 & 5.21 & -32.0 & 51.63 \\
\hline $\mathrm{H}_{2} \mathrm{~S}$ & -1.82 & -2.41 & 7.79 & -34.2 & 53.80 \\
\hline $\mathrm{CO}_{2}$ & -1.07 & -1.66 & 8.11 & -32.8 & 60.21 \\
\hline $\mathrm{C}_{2} \mathrm{H}_{6}$ & -1.26 & -1.85 & 10.00 & -39.8 & 77.76 \\
\hline
\end{tabular}

Analysis of table 1 shows that the hydrate formation with the several gases are not spontaneous at $298 \mathrm{~K}$, although with a negative interaction energy and enthalpy in all cases. The main reason for the positive change in Gibbs free-energy is du to the negative change in the entropy values. This becomes increasingly more negative with the gas size and imply in a higher organization of the system by virtue of a lower interaction between the water molecules in opposite faces of the cages $i$. The direct consequence is the increase in the cage volume because the attraction between the water molecules in opposite faces decreases when the distance increases. The negative change in entropy leads to the positive change in the Gibbs Free Energy at $298 \mathrm{~K}$.

\section{Conclusion}

The interaction energies and enthalpies for formation of the hydrates at room temperature and pressure are negative. However, due to the higher confinement in the cage, the Gibbs Free Energy values for all systems are positive. This is confirmed by the negative values for the entropy change. Furthermore, gases with higher volume promote expansion in the cage with two associated effects: weakening of hydrogen bonds of neighboring water molecules and weakening of the interaction between water molecules in opposite faces. The first effect destabilizes the structure because this interaction is important to cage formation and the second effect contributes to decrease stability reducing attraction between the water molecules.

\section{Acknowledgement}

CNPq, FAPERJ, PROPPi UFF.

\section{References}

1. Mohammadi-Manesh, H.; Ghafari, H.; Alavi, S.; Journal of Molecular Structure, 113, 157-166, 2017.

2. Sloan, E. D., Jr; Koh, C. Clathrate Hydrates of Natural Gases; CRC press: 2007.

3. Sun, N.; Li, Z.; Qiu, N.; Yu, X.; Zhang, X.; Li, Y.; Yang, L.; Luo, K. Q.; Huang, S. Du. Ab Initio Studies on the Clathrate Hydrates of Some Nitrogen- and Sulfur-Containing Gases. J. Phys. Chem. A, 121, 2620-2626, 2017. 